DOI: http://doi.org/10.21698/simi.2018.fp45

\title{
DETERMINATION OF SULFUR COMPOUNDS WITH A STRONG OLFACTORY IMPACT ON THE POPULATION
}

Raluca Diodiu, Toma Galaon, Vasile Iancu, Mihaela Petrescu, Mihai Bratu, Valeriu Danciulescu, Andreea Cozea

National Research and Development Institute for Industrial Ecology -ECOIND, 71-73 Drumul Podu Dambovitei, district 6, 060652, Bucharest, raluca.diodiu@incdecoind.ro, Romania

\begin{abstract}
The aim of this study was to develop an analytical method capable to determine mercaptans in air at low concentrations, lower than the ones that produce an olfactory discomfort. A reliable, rapid, and simple high performance liquid chromatography (HPLC) method was developed for the determination of mercaptans, a sulphur compounds class. The developed method can be successfully applied to the quantitative determination of four compounds (Methyl mercaptan, Butyl mercaptan, Ethyl mercaptan and Propyl mercaptan).
\end{abstract}

Keywords: butyl mercaptan, ethyl mercaptan, mercaptans, methyl mercaptan, propyl mercaptan, thiols

\section{Introduction}

A number of studies conducted by our team revealed the presence of sulphur compounds in different environmental matrices (Petrescu et al 2017, Nicolescu et al 2017). Of the sulphur compounds, particular attention is given to mercaptans (thiols) due to the olfactory discomfort they can create at very low concentrations.

These are regulated in Romanian legislation only for Methyl mercaptan, but it has been found that the limits in the legislation are higher than the threshold at which an olfactory discomfort occurs. The methods used and implemented at present in the country are designed to meet the limits of the legislation. The technique of molecular absorption spectrometry is the one recommended for these compounds according to the standards in use. The performance of this technique cannot detect low levels of sulphur compounds at the level at which an olfactory discomfort occurs.

The implementation of new analytical techniques, suggested in the literature (Moliner-Martı'nez et al 2013, Toyo'oka et al 1988, Bramantis et al 2004), such as liquid chromatography high performance for mercaptans would compensate for this drawback and could determine and quantify concentrations below the detectable olfactory threshold. 


\section{INTERNATIONAL SYMPOSIUM "THE ENVIRONMENT AND THE INDUSTRY", SIMI 2018, PROCEEDINGS BOOK}

\section{Materials and Methods}

All reagents and standards were prepared with ultrapure water $(0.1 \mathrm{~S} / \mathrm{cm})$ from a ultra pure water purification systems MilliPore.

The standards were purchased commercially and were from SPEX CertiPrep. The standards were realised in methanol. All intermediate dilutions were also carried out in methanol. Standards were of the folowing concentrations: $1000 \mu \mathrm{g} / \mathrm{ml}$ of methyl mercaptan, $1000 \mu \mathrm{g} / \mathrm{ml}$ of ethyl mercaptan, $1000 \mu \mathrm{g} / \mathrm{ml}$ of propyl mercaptan and $1000 \mu \mathrm{g} / \mathrm{ml}$ of butyl mercaptan.

These can also be prepared in the laboratory by purchasing the pure substance and dissolving it in methanol.

The ortho-phthalaldehyde reagent - OPA $\left(\mathrm{C}_{8} \mathrm{H}_{6} \mathrm{O}_{2}\right)$ was commercially purchased but can be realised in the laboratory by dissolving the o-phthalaldehyde in distilled water with $1 \%$ methanol.

The isoleucine reagent $\left(\mathrm{C}_{6} \mathrm{H}_{13} \mathrm{NO}_{2}\right)$ was prepared and brought to dry distilled water purchased as such from the trade. For the 7.4x10-3 M concentration, $0.9694 \mathrm{~g}$ of isoleucine is dissolved in $1000 \mathrm{ml}$ of ultrapure water.

The borate buffer solution at $\mathrm{pH}=10$ was prepared by dissolving boric acid and adjusting the $\mathrm{pH}$ with $1 \mathrm{M} \mathrm{NaOH}$. Dissolve $31 \mathrm{~g}$ of boric acid in $1000 \mathrm{ml}$ of ultrapure water. Sodium hydroxide used for $\mathrm{pH}$ adjustment was prepared in the laboratory from $\mathrm{NaOH}$ pellets and ultrapure water by dissolving $40 \mathrm{~g}$ of $\mathrm{NaOH}$ in $1000 \mathrm{ml}$ of ultrapure water.

\section{Results and Discussion}

Determination of thiols by liquid chromatography implies their derivatization to a more stable form using derivatizing agents. Subsequently, the derivatization compounds are analysed on a liquid-chromatograph.

A high-performance liquid chromatograph of Agilent 1200 coupled with a quaternary pump, autosampler and Fluorescence detector was used to perform the method. The chromatographic column used was Acclaim Carbonyl C18 with the following characteristics: $250 \mathrm{~mm} * 4.6 \mathrm{~mm}$, and particle size of $5 \mu \mathrm{m}$.

The mobile phase used was a mixture of methanol with gradient water and a flow rate of $1 \mathrm{ml} / \mathrm{min}$. In the literature, it is specified in case of derivatization with OPA-leucine eluting with methanol and water (Moliner-Martı'nez et al 2013).

Table 1. Gradient of the mobile phase.

\begin{tabular}{ccc}
\hline Timp (minute) & $\begin{array}{c}\mathrm{MeOH} \\
(\%)\end{array}$ & $\begin{array}{c}\mathrm{H}_{2} \mathrm{O} \\
(\%)\end{array}$ \\
\hline 0.0 & 25 & 75 \\
15.0 & 100 & 0 \\
17.0 & 100 & 0 \\
17.1 & 25 & 75 \\
\hline
\end{tabular}

In this method of mercaptans determination, various ratios between the mobile phase components (methanol: water) were tested to obtain the best separation in the shortest possible time. Separation was done using gradient elution in order to obtain efficient peaks in a short time period. The best gradient for the separation was a 5\%/minute methanol increase in 15 minutes as can be seen in Table 1. 


\section{INTERNATIONAL SYMPOSIUM "THE ENVIRONMENT AND THE INDUSTRY", SIMI 2018, PROCEEDINGS BOOK}

The stock standards were purchased commercially in a matrix of methanol (SPEX Certi Prep) containing $1000 \mu \mathrm{g} / \mathrm{ml}$ for each mercaptan (methyl mercaptan, ethyl mercaptan, propyl mercaptan, butyl mercaptan)

From the stock standards, intermediate standards were realised, containing a mix of each mercaptan, of $100 \mu \mathrm{g} / \mathrm{ml}$ and $2.5 \mu \mathrm{g} / \mathrm{ml}$ concentrations containing a mix all four thiols. From this, the points for the calibration curves were made and then derivatized.

The calibration curves ranged between 10-1000 $\mu \mathrm{g} / \mathrm{L}(\mathrm{ppb})$ for each of the four mercaptans. The calibration points were 10, 25, 50, 100, 250, 500, $1000 \mu \mathrm{g} / \mathrm{L} \mathrm{ppb).}$ The injection volume used in this analytical method was $50 \mu 1$.

The reaction of mercaptans (R-SH) with OPA and isoleucine underlies a very good capture / preconcentration / derivatization method minimizing the analytical problems specific to this analysis (instability and instability). According to the literature (Moliner-Marti'nez et al 2013), the best sensitivity to o-Phthaldialdehyde (OPA) and isoleucine derivatization was obtained with OPA 7.4 x 10-3 M and OPA: isoleucine (1: 1) ratio. With this in mind, each standard was derivatized as follows: $0.6 \mathrm{ml}$ of supernatant was added $0.4 \mathrm{ml}$ of borate buffer $(\mathrm{pH}=10), 1 \mathrm{ml}$ of the standard in methanol, $1 \mathrm{ml}$ of OPA followed by $1 \mathrm{ml}$ of isoleucine. It is expected to form a foam that leads to detergents.

The derivatization products are stable for 24 hours at room temperature, or 14 days (maximum study time) if stored at $4^{\circ} \mathrm{C}$. Under these conditions, derivatized mercaptan solutions were stored at $4^{\circ} \mathrm{C}$ in the refrigerator.

The determination coefficients - $\mathrm{R}^{2}$, had values greater than 0.999 , as follows: methyl mercaptan - 0.9994, ethyl mercaptan - 0.9996, propyl mercaptan - 0.9998 and butyl mercaptan -0.9999 .

Table 2. Retention time of compounds

\begin{tabular}{c|cccc} 
& $\begin{array}{c}\text { Methyl } \\
\text { mercaptan }\end{array}$ & $\begin{array}{c}\text { Ethyl } \\
\text { mercaptan }\end{array}$ & $\begin{array}{c}\text { Propyl } \\
\text { mercaptan }\end{array}$ & $\begin{array}{c}\text { Butyl } \\
\text { mercaptan }\end{array}$ \\
\hline $\begin{array}{c}\text { Retention time } \\
\text { (minutes) }\end{array}$ & 10.89 & 11.41 & 12.54 & 13.17
\end{tabular}

The analytical method of determination manages to separate the four mercaptans in a relatively short time, they eluted in less than 20 minutes, as can be seen in Table 2 . 


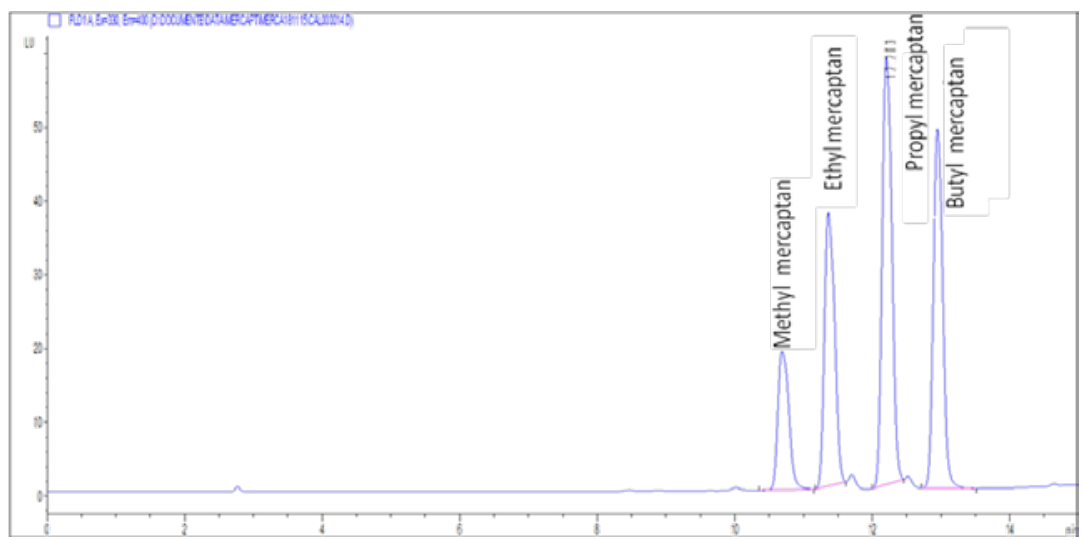

Figure 1. Chromatographic separation of mercaptans for the $500 \mathrm{ppb}$ standard.

Figure 1 shows a chromatogram of a standard sample used to perform calibration curves. Within this, one can follow the elution pattern of the compounds of interest.

\section{Conclusions}

In the present paper an analytical method was developed to identify and determine a class of sulfur compounds with strong olfactory impact on the receptors called mercaptans or thiols.

The analytical method was performed on a high performance liquid chromatograph and is able to identify and quantify under the limits of the legislation and near the olfactory threshold four compounds of the mercaptan class (mercaptan metal, ethyl mercaptan, propyl mercaptan and butyl mercaptan) in ambient air and indoor air samples.

The developed analytical method from this article can be reproduced by other analyst thus being able to be easily implemented in another laboratory. It also offers an alternative to methyl mercaptan determination by molecular absorption spectrometry, being more accurate in identifying methyl mercaptan from other mercaptans.

\section{Acknowledgements}

This work was carried out through the Romanian Nucleu Programme, developed with the support of MCI; the authors would like to thank all those who contributed to this study.

\section{References}

Bramanti, E, D’Ulivo, L, Lomonte, C, Onor, M ,Zamboni, R, Raspi, G \& D’Ulivo, A 2004, 'Characterization of denatured metallothioneins by reversed phase coupled with on-line chemical vapour generation and atomic fluorescence spectrometric detection', Journal of Chromatography A.,vol. 1054, pp.285291. 


\section{INTERNATIONAL SYMPOSIUM "THE ENVIRONMENT AND THE INDUSTRY", SIMI 2018, PROCEEDINGS BOOK}

Moliner-Martınez, Y, Herraez-Hernandez, R, Molins-Leguan, C, Verdu -Andres, J, Avella-Oliver, M \& Campıns-Falco, P 2013, 'More about sampling and estimation of mercaptans in air samples', Talanta, vol. 106, pp.127-132.

Nicolescu, IC, Bucur, E, Serbanescu, A, Diodiu, R \& Barbu, ME 2017, 'Determination of sulphur content in waste materials by ion chromatography', $20^{\text {th }}$ International Symposium "The Environment and The Industry", SIMI 2017, National Research and Development Institute for Industrial Ecology ECOIND, Bucharest, pp. 242-247.

Petrescu, M, Bucur, E, Diodiu, R, Bratu, M, Serbanescu, A \& Barbu, M 2017, 'Chemical characterization of wet depositions in urban and rural area', $20^{\text {th }}$ International Symposium “The Environment and The Industry”, SIMI 2017, National Research and Development Institute for Industrial Ecology ECOIND, Bucharest, pp. 213-220.

Toyooka, T, Uchiyama, S, Saito, Y \& Imai, K 1988,'Simultaneous determination of thiols and disulfides by high-performance liquid chromatography with fluorescence detection', Analytica Chimica Acta, vol. 205, pp. 29-41. 